Research Article

\title{
Fracture Characteristics and Geometric Fractal of Damaged Sandstone under Impact Load
}

\author{
Hao Hu, ${ }^{1}$ Qiangqiang Zheng $\mathbb{D}^{1,2}$ Xin Gao, ${ }^{1}$ Bing Cheng, ${ }^{1}$ Qianqian Wang, ${ }^{1,2}$ and Xian $\mathrm{Ni}^{1,2}$ \\ ${ }^{1}$ State Key Laboratory of Mining Response and Disaster Prevention and Control in Deep Coal Mines, \\ Anhui University of Science and Technology, Huainan, Anhui 232001, China \\ ${ }^{2}$ School of Civil Engineering and Architecture, Anhui University of Science and Technology, Huainan, Anhui 232001, China
}

Correspondence should be addressed to Qiangqiang Zheng; qiangqz@163.com

Received 9 October 2020; Revised 29 October 2020; Accepted 30 October 2020; Published 16 November 2020

Academic Editor: Chen Miao

Copyright (c) $2020 \mathrm{Hao} \mathrm{Hu}$ et al. This is an open access article distributed under the Creative Commons Attribution License, which permits unrestricted use, distribution, and reproduction in any medium, provided the original work is properly cited.

\begin{abstract}
Before the rock mass in the engineering is broken under load, it is usually in a state of varying degrees of damage. Aiming at the fracture characteristics of damaged sandstone under impact load, this paper adopts a method of the cyclic static load to cause the sandstone specimens to have varying degrees of damage. Then, the wave velocity of sandstone before and after the damage is measured using the nonmetallic acoustic velocimeter, and the change rule of damage factor is analyzed. Finally, the split Hopkinson pressure bar (SHPB) is used to test the impact dynamics of sandstone with different damage degrees. The broken rock block is screened by a vibrating screen, and the crushing characteristics are analyzed. The results show that not only the damage factor of damaged sandstone but the growth rate increases, with the raising upper limit of stress. Under the impact load of the same incident energy, the fragmentation degree of the damaged sandstone increases with the increase of the upper stress limit, while the average diameter of the broken rock block decreases gradually, and the reduction rate increases first and then decreases.
\end{abstract}

\section{Introduction}

Rocks are widely found in geotechnical engineering, such as coal mine roadways, tunnel engineering, roadbed engineering, water conservancy dams, and rock slopes $[1,2]$. The natural rock is a complex geological fractured medium, with randomly distributed defects, such as joints and fractures $[3,4]$. In addition, the rocks in geotechnical engineering are affected by human mining activities, which results in varying degrees of damage, weakening the surface and complicating the internal mesostructure in the rock. Therefore, in this case, it is unreasonable to analyze the rock as a nondestructive original rock and use its mechanical properties and deformation characteristics.

When the bearing capacity of the rock is not enough to withstand the deformation caused by the load, the rock will become unstable and even fail. The fracture characteristics of the rock are related to the physical and mechanical properties of the rock, internal mesostructure, load type, strain rate, and temperature [5-7]. Many scholars analyzed the failure laws and fracture characteristics of rocks based on strain rate, confining pressure, and temperature with two kinds of loading methods, that is, static load and dynamic load, and the corresponding fracture characteristics models were constructed [8-10]. These research results have established a theoretical foundation for engineering practice and at the same time successfully guaranteed the safe of engineering production. However, the rock masses in geotechnical engineering such as mines and tunnels are affected by mining activities of varying degrees of repeated loading and unloading, leading to varying degrees of degradation inside the rock. There are also differences in the scale, size, and form of cracks in rocks with different damage levels, as well as the characteristics of broken rock blocks after loading. To study the fracture characteristics of rocks under load is of great significance for analyzing the characteristics of rock burst dynamic disasters and the relief of rock bursts.

Many researchers have carried out a series of studies on the fracture characteristics of rocks. Li et al. [11] studied the 
deformation characteristics of rocks under uniaxial load and analyzed the rock burst tendency and fracture characteristics of different types of rocks by employing the acoustic emission technology. Hasanipanah et al. [12] investigated the state and law of rock fragmentation based on 52 rock blasting events and compared and discussed adverse blasting events. Bahrami et al. [13] built a rock blasting and fragmentation prediction model using the artificial neural network, based on the rock lithology, fracture geometry, and explosive charge. Fabio et al. [14] proposed a rock avalanche crushing model based on the rock avalanche fragmentation characteristics, assuming that the rock fragmentation occurred on the force chain of van der Waals force in the granular medium inside the rock. Zhou et al. [15] adopted the SHPB to explore the fracture characteristics of rocks at different strain rates and concluded that the higher the strain rate, the greater the degree of rock fracture. Zhu et al. [16] explored the basic principles of the combined dynamic and static loading of rocks, and the stress distribution, damage evolution, and fracture characteristics in the rock were analyzed by RFPA dynamic numerical simulation. Shen et al. [17] used the discrete element method to analyze the factors of rock fracture caused by impact load and summarized the rock fracture characteristics. The abovementioned scholars analyzed the breaking characteristics of rock from both static and dynamic aspects and made detailed research on the rupture characteristics of rock in many aspects. However, the analysis is based on the nondamaged state of the rock, and the factors that cause damage to the rock in the engineering under cyclic loading are not considered. The existence of weak surfaces such as joints and cracks in the rock weakens the structural integrity of the rock, of which the fracture characteristics are different from those of undamaged rocks.

Most of the rocks buried deep in coal mines are in different damage states due to mining disturbances. When dynamic disasters such as rock burst and coal and gas outburst appear, the broken state of the rock and the propagation law of the dynamic carrier are affected by the joints and weak surfaces in the rock [18]. In this study, the influence of cyclic load on the rock is considered, and the fracture characteristics under dynamic load based on different damage levels of the rock are analyzed. For the sake of exploring the fracture characteristics of damaged rocks under impact load, based on the Kaiser effect of rocks [19], the author uses cyclic loads applied on sandstone specimens with different upper stress limits to cause them to have different degrees of damage. Then, the SHPB is adopted to conduct dynamic mechanical tests on sandstones with different levels of damage. Finally, the broken rock block is analyzed by a geometric fractal method, and the breaking characteristics of sandstone with different damage degrees under impact load are explored.

\section{Experimental Equipment and Experimental Scheme}

2.1. Preparation of Rock Samples. In this test, in situ sampling was taken from the coal roof of a mine in Huainan Mining
Area, Anhui Province, China. The lithology is sandstone. Based on the standards of the International Society for Rock Mechanics and Rock Engineering, the cylinder sample with a size of $\Phi 50 \mathrm{~mm} \times h 25 \mathrm{~mm}$ was prepared after cutting and grinding in the laboratory. The flatness error of the two ends of the test piece should be controlled below $0.01 \mathrm{~mm}$, and the nonparallelism of the two ends should be less than $0.05 \mathrm{~mm}$. The partially processed rock samples are shown in Figure 1.

2.2. Experimental Device and Experimental Scheme. Four sets of experimental devices are mainly employed in this experiment, namely, MTS816 rock mechanics test system, SHPB test system, nonmetallic sonic velocimeter, and vibrating screen. The MTS816 is used to measure the strength of sandstone and conduct cyclic loading and unloading damage tests on sandstone specimens. It should be noted that the measurement of the strength of sandstone with a cylindrical specimen of $\Phi 50 \mathrm{~mm} \times h 25 \mathrm{~mm}$ is not used to calibrate the actual standard uniaxial compressive strength, but the upper limit of the cyclic load. Nonmetallic sonic velocimetry is used to measure the wave velocity before and after sandstone damage and determine the damage factor of the damaged sandstone. Besides, the SHPB is adopted to study the breaking characteristics of the rock, and then a geometric fractal test is performed on the broken rock blocks with a vibrating screen to analyze the fragmentation distribution of the damaged sandstone under impact load.

First, a static mechanical experiment was performed on the sandstone specimen to determine its strength, and the sandstone specimen was loaded with a force-time loading method at a loading rate of $500 \mathrm{~N} / \mathrm{s}$. The average compressive strength of the sandstone specimen was determined and recorded as $\sigma_{b}$. Then, different upper stresses were imposed on the sandstone specimens, causing different levels of damage. The upper stress limits are $20 \% \sigma_{b}, 40 \% \sigma_{b}, 60 \% \sigma_{b}$, and $80 \% \sigma_{b}$, respectively, and the loading rate is also $500 \mathrm{~N} / \mathrm{s}$. And the number of cycles is 10 times. Before and after the sandstone is subjected to the cyclic load, a nonmetallic acoustic wave monitor is used both to measure the wave velocity of the rock and to analyze the damage degree of the sandstone. Finally, an impact load is applied to the damaged sandstone with different levels of damage. Afterwards, the broken rock pieces and cuttings of each sandstone after the impact load are collected separately with a sample bag. Then, a group of vibrating screens with aperture gradients of $31.5 \mathrm{~mm}, 26.5 \mathrm{~mm}, 19 \mathrm{~mm}, 10 \mathrm{~mm}, 4.75 \mathrm{~mm}, 2.36 \mathrm{~mm}$, $1.25 \mathrm{~mm}, 0.63 \mathrm{~mm}$, and $0.3 \mathrm{~mm}$ are selected for screening to analyze the crushing characteristics of sandstone under impact load. The experimental device and test process are shown in Figure 2.

2.3. Dynamic Stress Balance Verification. Before the SHPB test, the SHPB system should be verified for dynamic stress balance. It is assumed that any plane in the specimen remains flat during the propagation of the stress wave in the sandstone specimen, and there is only uniformly distributed axial stress on the cross section. Through the dynamic stress balance verification of the stress wave of each sandstone 


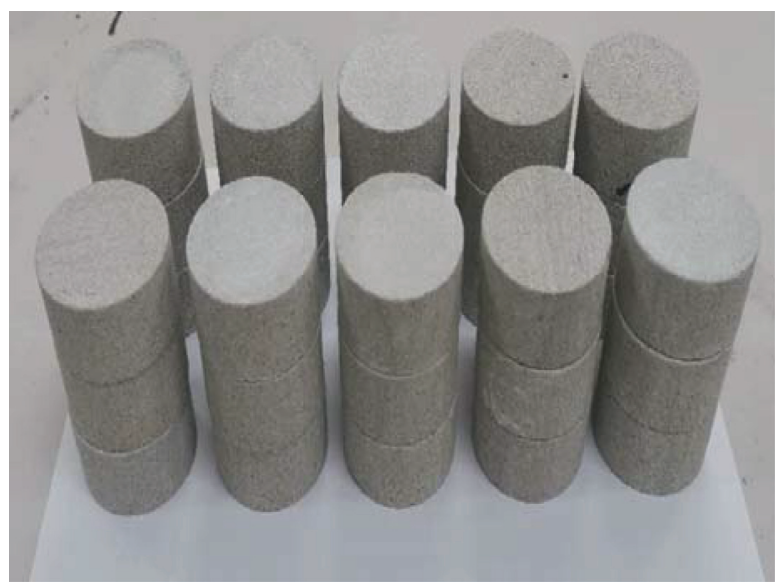

Figure 1: Partial sandstone samples.

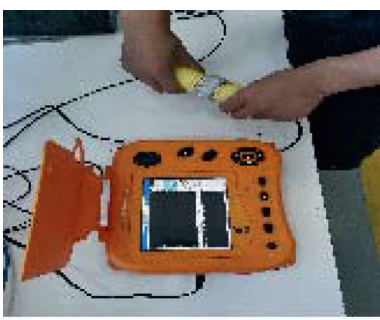

(1) The nonmetalic sonic velocimeter is used to measure the wave velocity changes of sandstone before and after damage.

(2) Cyclic loading and unloading with different upper stress limits makes the rock have different degrees of damage, and then the static mechanical strength is measured.

(a)
Loading device
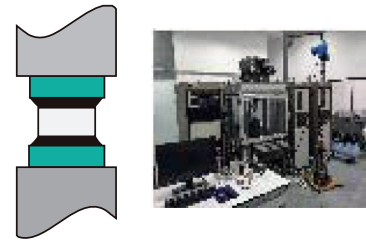

(3) Cyclic loading and unloading with different upper stress limits makes the sandstone have different degrees of damage, and then carry out the impact and mechanical tests.
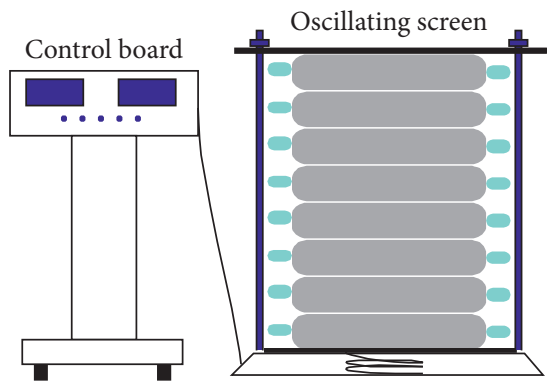

(4) Conduct impact dynamic experiments on sandstone with different damage degrees.

(5) Using screens with different apertures to screen and fractal the broken rock (b) (c)

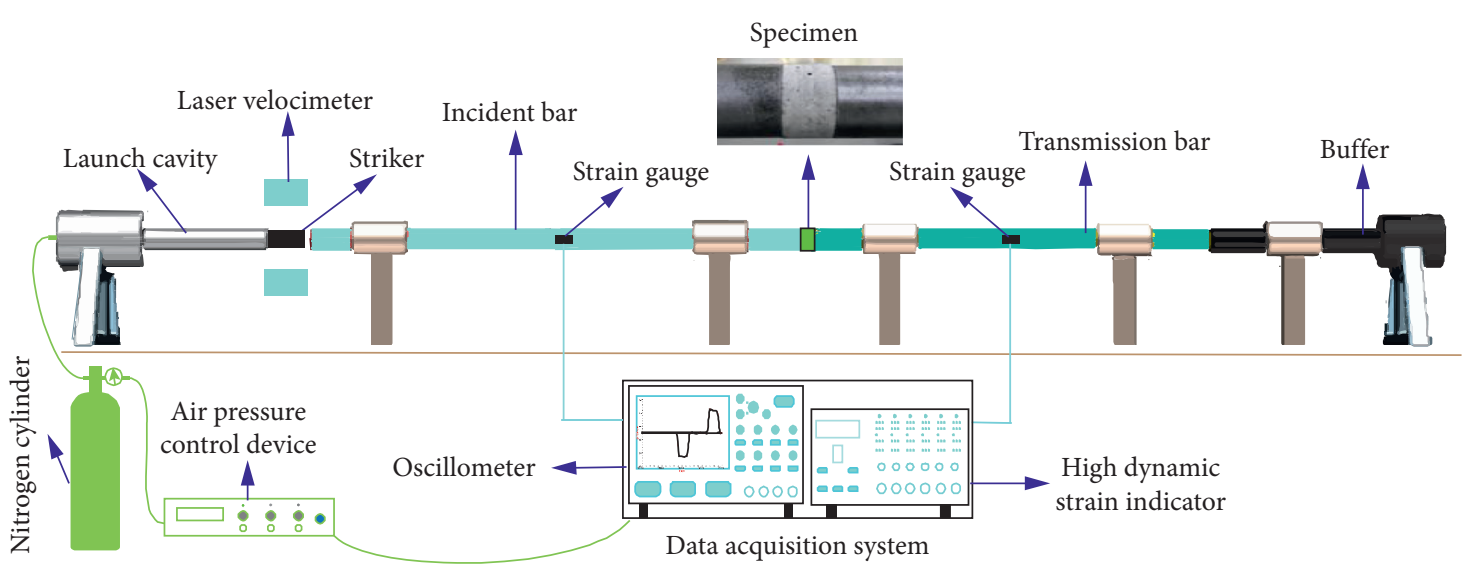

(d)

Figure 2: Experimental device and test flowchart.

specimen under the impact load, the dynamic stress balance is determined and then analyzed. By analyzing the results of the stress balance test, it can be known that the stress of the sandstone specimen under the impact load complies with the stress balance assumption. This indicates that the processing and placement of sandstone specimens meet the assumption of the one-dimensional stress wave, which also reveals the rationality of the test results. 


\section{Experimental Results}

3.1. The Law of Static Damage. After the sandstone specimens were subjected to the cyclic load by the MTS816 rock mechanics test system, different degrees of damage occurred. Table 1 shows the wave speed test results of sandstone before and after the cyclic loading. From Table 1, it can be seen that the wave speeds of sandstone samples with different degrees of damage after cyclic loading are reduced. This is because after the cyclic load is applied to the sandstone specimens, cracks in the rock initiate and develop. And with the increase of the upper stress limit, the larger the size of the cracks in the rock, the higher the degree of damage. The change of the acoustic wave velocity of rock is positively correlated with its strength, that is, the greater the decrease of the wave velocity, the more obvious the decrease of the strength of the specimen. The change of the acoustic wave velocity of the rock can characterize its damage degree.

From the point of view of damage mechanics, Lemaitre [20] proposed the concept of continuous damage mechanics under the premise of considering the whole process of material failure. The damage constitutive equation is defined as equation (1), based on the strain equivalence hypothesis under the one-dimensional problem:

$$
\sigma=E(1-D) \mathcal{\varepsilon}
$$

where $\sigma$ is the real stress on the damaged sandstone, $\mathrm{MPa}$; is the strain when the stress on the sandstone is $\sigma$; $E$ is Young's modulus of the undamaged sandstone, $\mathrm{MPa} ; \mathrm{D}$ is the damage factor, which represents the degree of damage inside the sandstone specimen; $D=0$ means a complete material without damage and $D=1$ is equivalent to the destruction of the volume element; and $(1-D)$ is the ratio of the effective bearing area to the total area.

Based on the classical damage mechanics theory [21], the two damage factors are defined as the following two expressions, respectively: (1) $D=1-A / A_{0}$ is defined by the effective bearing area of the structure, where $A$ represents the effective bearing area after sandstone damage, $\mathrm{m}^{2}$, and $A_{0}$ represents the bearing area of the sandstone without damage, $\mathrm{m}^{2}$; (2) $D=1-E / E_{0}$ is defined from the point view of elastic modulus, where $E$ represents the elastic modulus of the damaged sandstone, $\mathrm{MPa}$, and $E_{0}$ represents the elastic modulus of the undamaged sandstone, $\mathrm{MPa}$.

In the light of the nonmetallic velocimeter, when the propagation of wave encounters the microdefects in the material, the wave speed attenuates, which can reflect the change of the dynamic elastic modulus of the material. Based on the second definition of damage factor, the relationship between damage factor and wave velocity is established, and the damage change of sandstone under cyclic load is obtained.

According to the stress wave theory, the initial longitudinal wave velocity $C_{0}$ and the damage longitudinal wave velocity $C$ of the rock are formulated in equations (2) and (3), respectively:

$$
\begin{gathered}
C_{0}=\sqrt{\frac{E_{0}(1-\mu)}{\rho(1-2 \mu)(1+\mu)}}, \\
C=\sqrt{\frac{E(1-\mu)}{\rho(1-2 \mu)(1+\mu)}},
\end{gathered}
$$

where $\mu$ represents Poisson's ratio of the material and $\rho$ represents the density of the material.

Through mentioned above, the damage factor defined by the elastic modulus of the damaged sandstone can be obtained, as shown in equation (4). Consequently, the damage factor obtained by calculating the measured wave velocity is shown in Table 1:

$$
D=1-\left(\frac{C_{0}}{C}\right)^{2} .
$$

From the wave velocity measurement results of the damaged sandstone, it can be seen that the damage degree of the rock increases with the increase of the upper limit of the cyclic load stress. In order to analyze the change law more intuitively, the damage factor is fitted, as shown in Figure 3. From Figure 3, it can be seen that the damage factor of sandstone increases with the increase of the upper limit of the cyclic load stress, and it obeys the Weibull distribution model. The fitted curve is $y=1-\exp \left[-(x / 1.1824)^{3.4145}\right]$, and the degree of fit is $R^{2}=0.9967$, indicating that the goodness of fit is high. Furthermore, the damage factor of damaged sandstone increases with the increase of the upper stress limit, and the higher the upper stress limit, the faster the damage factor increases, which is closely related to the mechanical properties of sandstone.

When the upper stress limit is less than $40 \% \sigma_{b}$, the reasons for internal microscopic changes of sandstone under load are mainly the compaction and closure of primary pores and the elastic deformation of solid mineral particles. While the rock is loaded, its internal resistance to deformation is mainly solid mineral particles [22]. When the upper limit of the cyclic static load stress is lower than $40 \% \sigma_{b}$, most of the rock deformation in this range can be recovered with the removal of external force, and only a small amount of the cracking of the cemented matrix and the closure of the primary pores cannot be recovered [23]. Stress concentration and local damage are generated in some of the larger microvoids, while the rest are mainly elastic deformation. At this time, the cracks in the damaged sandstone are in smaller scale. Therefore, the damage factor is low and the growth rate is slower. When the upper limit of the cyclic load stress is increased to $60 \% \sigma_{b}$, the scale and size of the cracks in the damaged sandstone increase. At the moment, the cracks have not yet penetrated [24]. Compared with the number of cracks when the upper stress limit is lower than $40 \% \sigma_{b}$, the number of cracks in this case is more and the size of the cracks is relatively large. When the stress is within the range of this stage, the plastic deformation of sandstone accounts for a larger proportion of the overall deformation than the previous two stages, and both the damage factor and the growth rate have greatly increased. When the upper limit of 
TABLE 1: Wave velocity change table before and after sandstone is subjected to cyclic loading.

\begin{tabular}{lcccc}
\hline$(\%)$ & Initial wave velocity & Wave velocity after damaged & Damage factor & Average damage factor \\
\hline \multirow{2}{*}{$20 \sigma_{b}$} & 3201.5206 & 3168.1111 & 0.020762 & 0.020691 \\
& 3221.5006 & 3189.7009 & 0.019645 & 0.021665 \\
$40 \sigma_{b}$ & 3213.2865 & 3178.2879 & 0.087975 & 0.087022 \\
& 3226.9230 & 3081.7120 & 0.084660 & 0.088431 \\
$60 \sigma_{b}$ & 3307.9461 & 3164.8239 & 0.244292 & 0.250664 \\
& 3266.3903 & 3118.6236 & 0.258209 & 0.249491 \\
$80 \sigma_{b}$ & 3291.5206 & 2861.3674 & 0.571687 & 0.562000 \\
& 3284.1357 & 2828.5371 & 0.550242 & 0.564070 \\
\hline
\end{tabular}

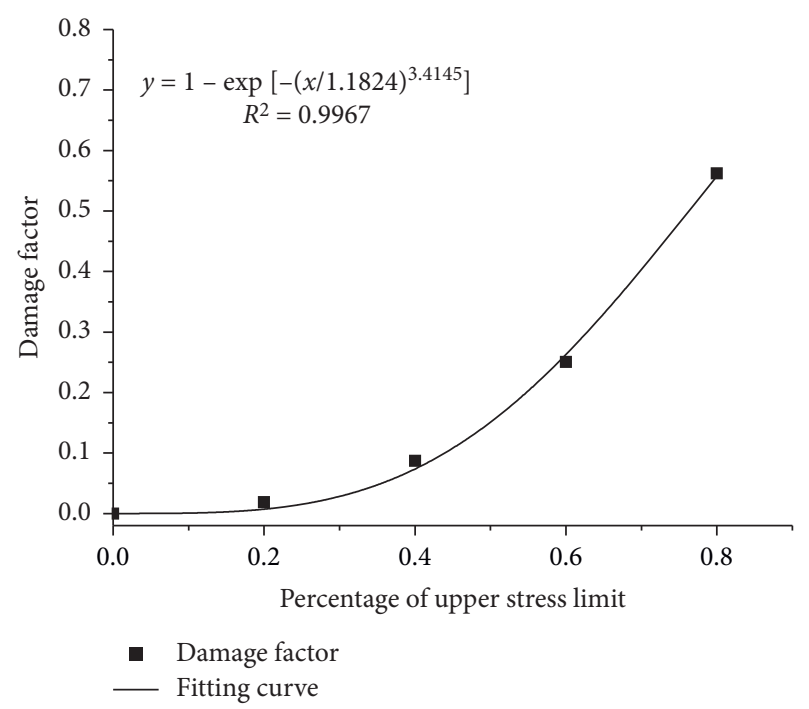

Figure 3: Variation law between damage factor and upper stress limit.

the cyclic static load stress reaches to $80 \% \sigma_{b}$, the cracks in the sandstone expand rapidly under the continuous action of the load, inducing secondary cracks, and the crack of rock enters the unstable crack propagation stage [25]. The scale and size of the cracks in the damaged sandstone have reached its maximum, and some cracks have formed through. However, the main fissure has not been penetrated, and the sandstone still maintains a macroscopic overall state, but the number of internal fissures cannot be directly observed whether it reaches its maximum. At this time, the sandstone still has a certain bearing capacity. After removing the external load acting on the sandstone, most of the cracks that generated in the sandstone cannot be restored [25]. In this stage, both the damage factor of the damaged sandstone and the growth rate of the damage factor reach their maximum.

In summary, as the upper limit of stress increases, the damage factor of sandstone gradually increases. When the upper limit of stress is less than $40 \% \sigma_{b}$, the growth rate of the damage factor is small but still increasing. When the upper limit of stress is raised continuously, the growth rate is incremental gradually. The changes in the scale and scale of internal fractures of sandstone after different cyclic static load stress upper limits are the main reasons for the reduction of macroscopic strength.

3.2. Analysis of Crushing Characteristics. In this study, by analyzing the damage factors of the sandstone after cyclic loading with different upper stress limits, the law of damage factors of damaged sandstone changing with the increase of upper stress limits is obtained. According to the impact dynamic experiment results of sandstone with different damage degrees, it can be seen that under the same strain rate, the greater the damage factor of sandstone, the more the broken rock blocks and the smaller the average diameter after impact load. This result is consistent with the dynamic response of the rock mass when the coal mine dynamic disaster appears, and it also agrees with the dynamic mechanical properties of sandstone under the traditional impact load. Predecessors have achieved relatively mature research results on the dynamic mechanical properties of sandstone under different strain rates [26-28]. Therefore, the fracture characteristics of damaged sandstone under different strain rates will not be repeated in this study. To analyze the fracture characteristics of sandstone with different damage degrees under the same strain rate, this paper focuses on the damage degree of sandstone as a variable. Through dynamic mechanical tests on the sandstone with different classes of damage, the stress wave propagation of sandstone with different damage degrees under impact load is shown in Figure 4.

From Figure 4, it can be known that under the same driving pressure, the incident waves of all sandstone specimens are basically the same, but the reflection waves and transmission waves are different in size. The sandstone specimens are in different degrees of damage subjected to cyclic static loading, and there are fissures of different scales, sizes, and forms inside them. The existence of these cracks affects the propagation of stress waves. The more damage sandstone specimens have, the more internal cracks and the larger the size of the cracks, and vice versa. When the incident stress wave propagates from the incident bar to the sandstone specimen, and then from the sandstone specimen to the transmission bar, the reflection and transmission of the stress wave occur [28]. Cracks are intricately distributed 


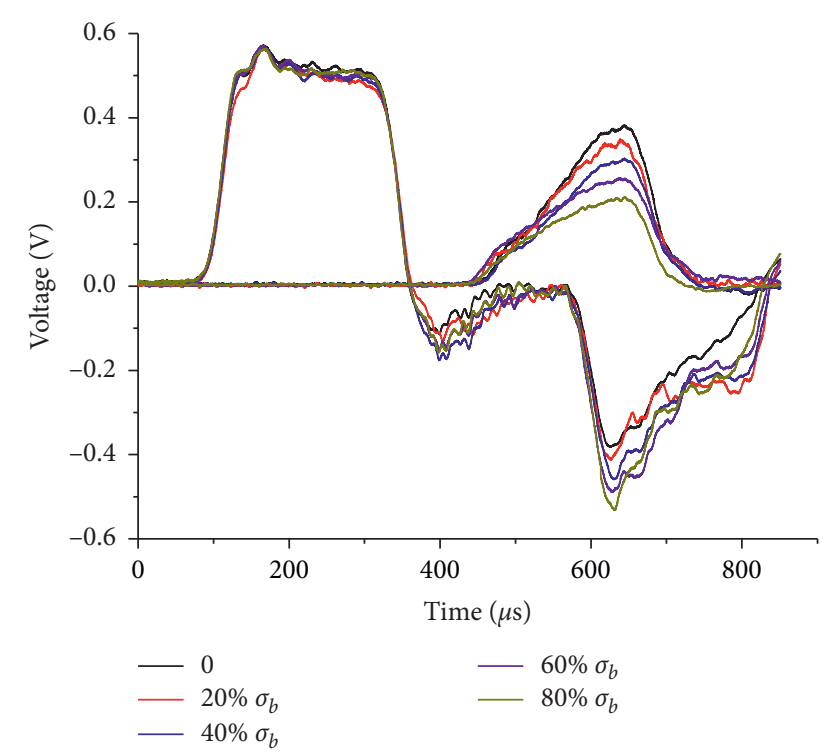

Figure 4: Schematic diagram of stress wave propagation in sandstone with damage degree under impact load.

in the damaged sandstone, and the number of incident stress waves reflected and transmitted increases with the increase of the number of cracks. Therefore, when the upper limit of stress increases, the reflected wave increases, and the transmitted wave decreases [28]. With the increase of the upper stress limit, the scale, size, and gap width of the cracks in the damaged sandstone gradually increase. On the one hand, with the crack tip effect, the energy required during the crack propagation process is less than the energy required without a crack, which weakens the ability of the specimen to absorb energy. On the other hand, it can be explained from the conservation of energy that under static load, the greater the upper stress limit, the more cracks in the sandstone, and the less energy is needed to break the specimen under impact load [29]. Therefore, as the upper limit of stress increases, the degree of rock fragmentation increases, while the fragmentation of the rock tends to decrease. In addition, the more the number of cracks, the more times the stress wave will be emitted and transmitted, that is, the more cracks the stress wave passes through, the more the attenuation times will occur. When the gap is larger, the amplitude of attenuation will be greater [30]. Therefore, under the impact load of the same magnitude of the incident wave, the more the number of cracks and the larger the interval of the damaged sandstone, the smaller the fragmentation of the broken rock block when it is broken by the impact load.

In order to analyze the breaking characteristics of sandstone with different damage degrees under impact load more intuitively, the broken rock blocks of sandstone with different damage degrees are screened one by one. Vibrating screens with aperture gradients of $31.5 \mathrm{~mm}, 26.5 \mathrm{~mm}$, $19 \mathrm{~mm}, 10 \mathrm{~mm}, 4.75 \mathrm{~mm}, 2.36 \mathrm{~mm}, 1.25 \mathrm{~mm}, 0.63 \mathrm{~mm}$, and $0.3 \mathrm{~mm}$ are used to screen broken rock blocks, respectively. Figure 5 shows the broken state of sandstone with different damage degrees.
The failure modes of sandstone with different damage levels under impact load are comparatively analyzed. It is found that the nondestructive sandstone fails radially under impact load, and the specimen is divided into two parts as a whole at the initial stage. As the upper limit of stress increases, the number of broken rock blocks gradually increases, the diameter of broken rock blocks gradually decreases; the number of solid mineral particles also gradually increases, and the degree of crushing of the cemented matrix gradually increases. The average diameter method is used to analyze the fragmentation degree, and the average diameter $\bar{d}$ of the broken rock block can be obtained by equation (5). The geometric screening mass distribution and average diameter of broken rock blocks are shown in Table 2.

$$
\bar{d}=\frac{\sum_{i=1}^{n} m_{i} d_{i}}{m},
$$

where $m$ is the mass of the specimen, $g ; m_{i}$ is the mass of the broken concrete between adjacent aperture screens, g; and $d_{i}$ is the average diameter of the two sieve holes corresponding to $m_{i}$, which are $31.5 \mathrm{~mm}, 26.5 \mathrm{~mm}, 19 \mathrm{~mm}, 10 \mathrm{~mm}$, $4.75 \mathrm{~mm}, 2.36 \mathrm{~mm}, 1.25 \mathrm{~mm}, 0.63 \mathrm{~mm}$, and $0.3 \mathrm{~mm}$ in descending order.

From the geometric fractal test results in Table 2, it can be seen that the average diameter of broken rock blocks decreases with the increase of sandstone damage. In order to more intuitively analyze the fracture characteristics of damaged sandstone under impact load, the average diameter of the broken rock block is fitted, as shown in Figure 6 .

From Figure 6, after the damaged sandstone is broken by impact load, the average diameter of the broken rock block gradually decreases with the increase of the upper limit of the cyclic static load stress, and the reduction rate is closely related to the static damage factor of the damaged sandstone.

When the upper stress limit is less than $20 \% \sigma_{b}$, the average diameter of the broken rock block decreases slightly with a lower decrease rate. With the increase of the upper limit of stress, the decrease amplitude increases, and the decrease rate increases. Until the upper limit of stress exceeds $60 \% \sigma_{b}$, the reduction rate of the average diameter of crushed rock blocks slows down, while the average diameter still decreases. The static load damage factor is combined with the average diameter of the broken rock block for intuitive analysis, and then the fracture characteristics of the damaged sandstone under the impact load are analyzed from the perspective of mechanical performance, as shown in Figure 7.

Taking the average diameter of undamaged sandstone of the broken rock masses under impact load as the reference point, when the upper stress limit is $20 \% \sigma_{b}$, the average diameter of broken rock masses decreases, but the reduction range is small with low decrease rate. Within the range of this stress stage, after the rock is subjected to static load, the internal primary pores are compacted and closed, and a small part of the microcavities are crushed, causing subdefects in a local area of the rock. In addition, the rock at this time is not ideal because only the primary pores are compacted and closed. And a small amount of cracking occurs 


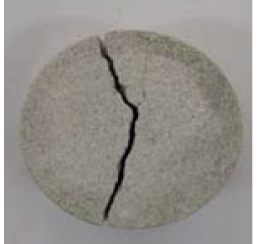

(a)

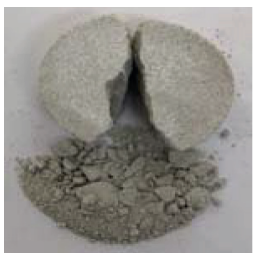

(b)

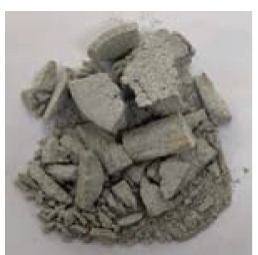

(c)

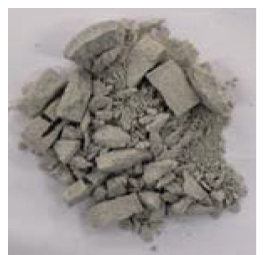

(d)

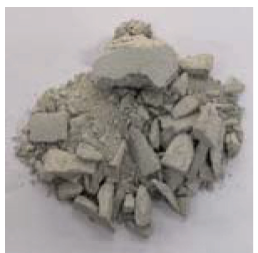

(e)

Figure 5: Fractured shape of damaged sandstone under impact load: (a) 0, (b) 20\%, (c) 40\%, (d) 60\%, and (e) $80 \%$.

TABLE 2: Size distribution of broken rock blocks of sandstone with different damage degrees under impact load.

\begin{tabular}{|c|c|c|c|c|c|c|c|c|c|c|c|}
\hline Upper limit of stress & $m(\mathrm{~g})$ & $31.5(\mathrm{~g})$ & $26.5(\mathrm{~g})$ & $19(\mathrm{~g})$ & $10(\mathrm{~g})$ & $4.75(\mathrm{~g})$ & $2.36(\mathrm{~g})$ & $1.25(\mathrm{~g})$ & $0.63(\mathrm{~g})$ & $0.3(\mathrm{~g})$ & $\bar{d}(\mathrm{~mm})$ \\
\hline \multirow{3}{*}{0} & 139.160 & 0 & 127.081 & 0 & 0 & 0 & 4.590 & 4.435 & 2.087 & 0.966 & \multirow{3}{*}{20.993} \\
\hline & 140.647 & 85.674 & 0 & 33.758 & 0 & 0 & 4.082 & 6.794 & 9.256 & 1.082 & \\
\hline & 138.815 & 0 & 126.464 & 0 & 0 & 0 & 5.029 & 4.740 & 2.189 & 0.394 & \\
\hline \multirow{3}{*}{$20 \% \sigma_{b}$} & 135.780 & 0 & 98.9463 & 25.985 & 3.497 & 2.683 & 0 & 1.578 & 1.444 & 1.647 & \multirow{3}{*}{19.770} \\
\hline & 137.192 & 0 & 103.398 & 24.652 & 3.473 & 1.454 & 0 & 0 & 1.873 & 2.342 & \\
\hline & 138.281 & 0 & 102.753 & 23.754 & 3.887 & 2.648 & 0 & 2.130 & 2.030 & 1.079 & \\
\hline \multirow{3}{*}{$40 \% \sigma_{b}$} & 136.685 & 0 & 62.463 & 44.768 & 11.548 & 4.548 & 4.937 & 2.1274 & 4.8593 & 1.433 & \multirow{3}{*}{16.182} \\
\hline & 136.082 & 0 & 62.749 & 47.674 & 9.335 & 3.335 & 3.356 & 2.9873 & 5.5766 & 1.069 & \\
\hline & 137.412 & 0 & 64.729 & 45.850 & 10.989 & 2.989 & 4.558 & 2.0879 & 4.1518 & 2.056 & \\
\hline \multirow{3}{*}{$60 \% \sigma_{b}$} & 139.662 & 0 & 37.356 & 45.854 & 28.278 & 8.038 & 4.257 & 5.1138 & 4.8492 & 5.915 & \multirow{3}{*}{12.414} \\
\hline & 139.8546 & 0 & 35.337 & 43.575 & 30.569 & 7.653 & 4.569 & 6.2376 & 6.3875 & 5.527 & \\
\hline & 136.9837 & 0 & 35.347 & 44.014 & 28.424 & 7.842 & 4.413 & 5.6053 & 5.618 & 5.721 & \\
\hline \multirow{3}{*}{$80 \% \sigma_{b}$} & 137.0231 & 0 & 30.165 & 32.868 & 30.656 & 8.073 & 8.755 & 8.5764 & 8.1538 & 9.776 & \multirow{3}{*}{10.362} \\
\hline & 138.5824 & 0 & 29.645 & 32.377 & 28.357 & 9.659 & 9.765 & 8.7548 & 9.4356 & 10.589 & \\
\hline & 140.2160 & 0 & 30.905 & 31.122 & 30.506 & 8.866 & 9.670 & 8.6689 & 8.7947 & 11.683 & \\
\hline
\end{tabular}

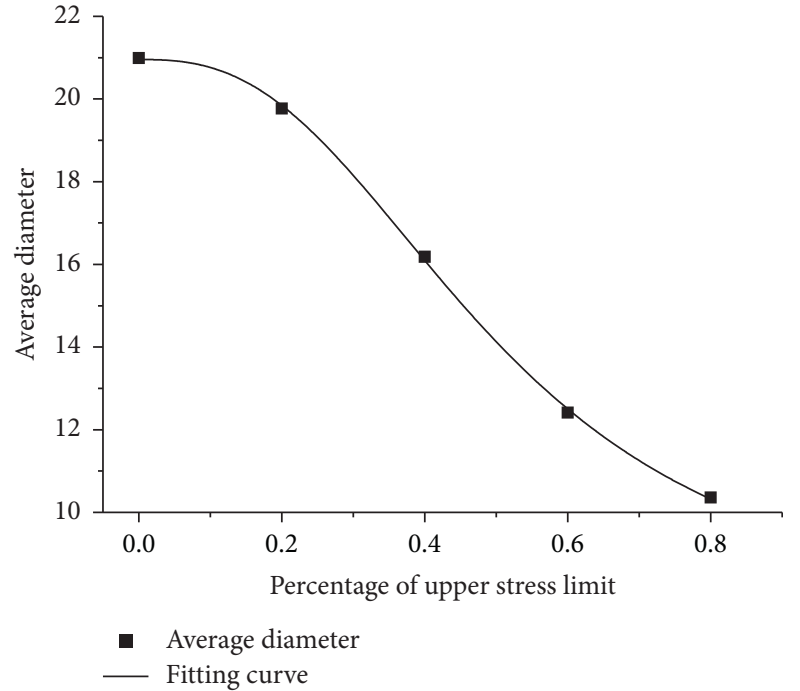

Figure 6: Curve of fitting relationship between the average diameter of broken rock block and the upper stress limit.

on the transition surface between some solid mineral particles and the cemented matrix. The existence of these cracks affects the propagation of the stress wave, and the extent of influence also varies with the size and scale of the crack. In the low stress range, due to the small size of the cracks in the damaged rock body, the propagation of the stress wave under the impact load is less affected. Therefore, compared with the nondestructive sandstone, the average diameter of the broken rock block of the damaged sandstone with a

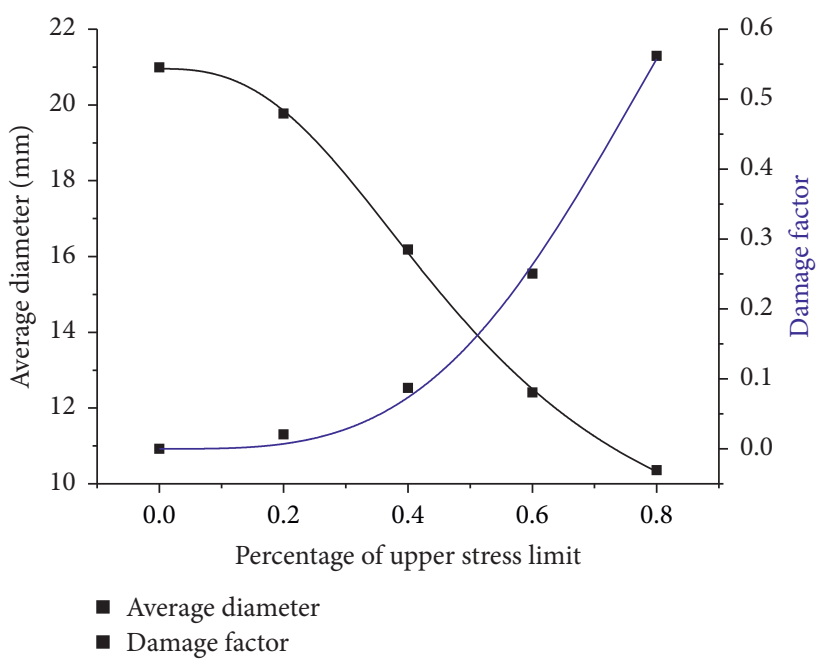

FIgURE 7: Fitting curve of fracture characteristics of damaged sandstone under impact load.

stress upper limit of $20 \% \sigma_{b}$ has a smaller change with a small decrease rate.

When the upper stress limit is increased to $40 \% \sigma_{b}$, at this time, although the increase in the damage factor of sandstone is small, the average diameter of the broken rock block is much lower than the average diameter when the upper stress limit is $20 \% \sigma_{b}$. This is because when the upper stress limit is $20 \% \sigma_{b}$, the primary pores in the sandstone are mainly compacted and closed, and when the upper stress 
limit increases to $40 \% \sigma_{b}$, the transition surface between the solid mineral particles in the rock and the cemented matrix is produced partially cracked. At this time, the static strength of the sandstone specimens did not change much, because although the transition surface cracked, most of the cracks are still in a closed state. When the sonic method is used to measure the damaged sandstone during this stress stage, most of the cracks are in a closed state due to the initiation of the transition surface. Therefore, the wave velocity decreases less with the damage factor increasing slightly. However, this kind of crack has a greater impact on the propagation of shock stress waves because the wave impedances of the solid mineral particles and the cemented matrix are not equal. When the transition surface is not cracked, it can be regarded as a whole. The cracks occur once the transition surface cracks. At this time, the stress wave attenuates under the combined effect of mismatch of wave impedance and cracks. Therefore, under the impact load of the same incident energy, compared with the damaged sandstone with the upper stress limit of $20 \% \sigma_{b}$, the damaged sandstone with a stress upper limit of $40 \% \sigma_{b}$ has a smaller average diameter of broken rock blocks after impact load, and the average rock mass reduction rate is also larger.

As the upper limit of stress continues to increase, the crack initiation scale of the transition surface becomes more and more larger. The number of cracks on the transition surface distributed in the rock gradually increases, and the width of the transition surface cracks is larger. As a result, the gap between the solid mineral particles and the cemented matrix is larger, and the stress wave decays faster here than in the previous two stages. Therefore, under the impact load of the same incident energy, the average diameter of the fragmentation of the damaged sandstone continuously decreases. When the upper stress limit is increased to $80 \% \sigma_{b}$, the cemented matrix in the rock begins to crack, and some of the cracks have been connected. The deformation at this time is irreversible after the external force is removed. The scale and width of the crack are all maximized, and the degree of reflection of the stress wave is greater, too. Due to the initiation and rapid expansion of the cemented matrix and the induction of secondary cracks, the scale of the cracks in the damaged sandstone with an upper stress limit of $80 \%$ $\sigma_{b}$ is much larger than those in the previous three stages. Therefore, the damaged sandstone with the upper stress limit of $80 \% \sigma_{b}$ under impact load is less broken than the damaged sandstone with the upper stress limit lower than $80 \% \sigma_{b}$, and the average diameter of the broken rock block is also the smallest. However, due to the large difference in the size of the cracks in the damaged sandstone at this time, there are cracks with both the larger and the smaller scales. The damage of sandstone under impact load is mainly caused by cracking and breaking along the cracks with large size. However, it is too late to crack for the subcracks of the smaller size have not had time to, while the damage of specimens has been produced along the cracks of the larger size. Therefore, when the upper stress limit is increased to $80 \% \sigma_{b}$, the average diameter of the broken rock mass decreases, but the decrease rate is the slowest among the previous three stages.

\section{Discussion and Conclusion}

The dynamic disasters such as rock bursts and coal and gas outbursts continue to restrict the safe production of coal mines severely. It becomes more difficult to prevent and control dynamic disasters under the complex and changeable geological environment. Many scholars use static load, dynamic load, and dynamic-static coupled loading methods to study the fracture characteristics of rock masses, but the fact that rock masses are often in different damage states affected by mining activities is ignored in most cases. There are obvious differences in the scale and scale of internal cracks in rock masses with different degrees of damage. When the dynamic disaster appears, the propagation of the stress wave is affected by the cracks, and the emission and transmission occur. The larger the scale and scale of the crack, the larger the reflected wave; the smaller the transmitted wave, the higher the degree of rock mass fracture.

Based on the dynamic response of damaged sandstone when coal mine dynamic disasters appear, this paper explores the fracture characteristics of sandstone with different damage degrees under impact load. On account of the upper limit of the cyclic static load stress, the fracture characteristics of the damaged sandstone under impact load are related to the scale and size of the cracks in the damaged sandstone and the mechanical characteristics of the damaged sandstone. At the same time, through geometric fractal of broken rock blocks that damage sandstone under impact load, the fractal dimension is used to analyze the characteristics of broken rock blocks of sandstone with different damage degrees after impact load, and the fragmentation characteristics are verified. Therefore, when analyzing the fracture characteristics of the rock mass in the dynamic disaster accident, the damage degree of the rock mass should be considered first. Then, based on the degree of damage and the development of cracks, the propagation law and breaking characteristics of the stress wave are analyzed, which may provide a certain reference for the prevention and control of adjacent mining areas, coal seams, and mines.

In this paper, based on the damaged sandstone under the cyclic static load of different upper stress limits, the damage factors of the damaged sandstone are analyzed. And combined with the mechanical characteristics and the scale and size of the cracks in the damaged sandstone, the fracture characteristics of the sandstone with different damage degrees under impact load are explored. Since it is difficult for the specimens with the upper limit of the cyclic static load stress to be greater than $80 \% \sigma_{b}$ to maintain the integrity, the analysis was not performed in this test. However, based on the test results, it is rational to verify that the upper stress limit is less than $80 \% \sigma_{b}$, in combination with rock mechanical properties. When the upper stress limit in the rock mass stress history is less than $80 \% \sigma_{b}$, this method is more reasonable. In addition, when the upper stress limit is greater than $80 \% \sigma_{b}$, the cracks in the sandstone enter the unstable expansion stage. Compared with when the upper stress limit is less than $80 \% \sigma_{b}$, the static damage factor increases faster, the damage of sandstone under impact load is more broken, and the average diameter of the broken rock block is smaller. 
Under cyclic static loading, the damage factor of sandstone is related to the upper limit of stress, which gradually increases with the increase of the upper limit of stress, and the growth rate also gradually increases. Under the impact load of the same incident energy, with the increase of the upper limit of the cyclic static load stress, the fracture degree of the damaged sandstone increases, while the average diameter of the broken rock block decreases.

Under different impact pressures, the research on the breaking law and fractal characteristics of sandstone has been very mature, so it will not repeat the complaint here. Focused on the fracture characteristics of damaged sandstone under the same impact pressure, the research results can provide references for the mechanism research of coal mine dynamic disasters.

\section{Data Availability}

The datasets generated and analyzed in the current study may be obtained from the corresponding author upon reasonable request.

\section{Conflicts of Interest}

The authors declare no conflicts of interest regarding the publication of this paper.

\section{Acknowledgments}

This work was funded by the National Natural Science Foundation of China (nos. 51574008 and 52004007) and Science Research Foundation for Young Teachers of Anhui University of Science and Technology (no. QN2018117).

\section{References}

[1] G. Zhang, L. Chen, Z. Wen et al., "Squeezing failure behavior of roof-coal masses in a gob-side entry driven under unstable overlying strata," Energy Science \& Engineering, vol. 8, no. 7, pp. 2443-2456, 2020.

[2] G. Zhang, S. Liang, Y. Tan, F. Xie, S. Chen, and H. Jia, "Numerical modeling for longwall pillar design: a case study from a typical longwall panel in China," Journal of Geophysics and Engineering, vol. 15, no. 1, pp. 121-134, 2018.

[3] M. C. He, J. L. Miao, and J. L. Feng, "Rock burst process of limestone and its acoustic emission characteristics under truetriaxial unloading conditions," International Journal of Rock Mechanics and Mining Sciences, vol. 47, no. 2, pp. 286-298, 2010.

[4] X. Li, Z. Li, E. Wang et al., "Pattern recognition of mine microseismic (MS) and blasting events based on wave fractal features," Fractals, vol. 26, no. 3, Article ID 1850029, 2018.

[5] V. A. Akinbinu, "Multivariate analysis of fracture toughness, brittleness and blasting geometric ratios for the prediction of fragmentation output," International Journal of Rock Mechanics and Mining Sciences, vol. 93, pp. 324-329, 2017.

[6] Y. Wang and F. Tonon, "Discrete element modeling of rock fragmentation upon impact in rock fall analysis," Rock Mechanics and Rock Engineering, vol. 44, no. 1, pp. 23-35, 2011.

[7] Z. J. Wen, X. Wang, Y. L. Tan, H. L. Zhang, W. P. Huang, and Q. H. Li, "A study of rockburst hazard evaluation method in coal mine," Shock and Vibration, vol. 2016, Article ID 8740868, 9 pages, 2016.

[8] X. F. Li, H. B. Li, Q. B. Zhang, J. L. Jiang, and J. Zhao, "Dynamic fragmentation of rock material: characteristic size, fragment distribution and pulverization law," Engineering Fracture Mechanics, vol. 199, pp. 739-759, 2018.

[9] Z. J. Wu, P. L. Zhang, L. F. Fan, and Q. S. Liu, "Numerical study of the effect of confining pressure on the rock breakage efficiency and fragment size distribution of a TBM cutter using a coupled FEM-DEM method," Tunnelling and Underground Space Technology, vol. 88, pp. 260-275, 2019.

[10] Y. Xu, W. Yao, S. Wang, and K. Xia, "Investigation of the heattreatment effect on rock fragmentation characteristics using the dynamic ball compression test," Rock Mechanics and Rock Engineering, vol. 53, no. 5, pp. 2095-2108, 2020.

[11] M. Li, Y. Song, and G. Zhang, "Study on the fractal characteristics of rock in the prediction of rockburst," RSC Advance, vol. 68, no. 7, pp. 43073-43082, 2017.

[12] M. Hasanipanah, D. J. Armaghani, M. Monjezi, and Samira Shams, "Risk assessment and prediction of rock fragmentation produced by blasting operation: a rock engineering system," Environmental Earth Sciences, vol. 75, no. 9, Document number: 808, 2016.

[13] A. Bahrami, M. Monjezi, K. Goshtasbi, and A. Ghazvinian, "Prediction of rock fragmentation due to blasting using artificial neural network," Engineering with Computers, vol. 27, no. 2, pp. 177-181, 2011.

[14] V. Fabio, D. Blasio, and G. B. Crosta, "Simple physical model for the fragmentation of rock avalanches," ACTA Mechanic, vol. 225, pp. 243-252, 2014.

[15] Z. Zhou, X. Li, Z. Ye, and K. Liu, "Obtaining constitutive relationship for rate-dependent rock in SHPB tests," Rock Mechanics and Rock Engineering, vol. 43, no. 6, pp. 697-706, 2010.

[16] W. C. Zhu, Y. Bai, X. B. Li, and L. L. Niu, "Numerical simulation on rock failure under combined static and dynamic loading during SHPB tests," International Journal of Impact Engineering, vol. 49, pp. 142-157, 2012.

[17] W.-G. Shen, T. Zhao, G. B. Crosta, and F. Dai, "Analysis of impact-induced rock fragmentation using a discrete element approach," International Journal of Rock Mechanics and Mining Sciences, vol. 98, pp. 33-38, 2017.

[18] A. Babak, A. Seyedsaeid, S. Javad, and B. Abbasi, "Stability analysis of rock structure in large slopes and open-pit mine: numerical and experimental fault modeling," Rock Mechanics and Rock Engineering, vol. 52, no. 12, pp. 4889-4950, 2019.

[19] M. K. Duan, C. B. Jiang, Q. Gan, M. H. Li, K. Peng, and W. Z. Zhang, "Experimental investigation on the permeability, acoustic emission and energy dissipation of coal under tiered cyclic unloading," Journal of Natural Gas Science and Engineering, vol. 73, Article ID 103054, 2020.

[20] J. Lemaitre, A Course on Damage Mechanics, Spring-Verlag, Berlin, Germany, 1992.

[21] H. Xie, Damage Mechanics of Rock and Concrete, China University of Mining and Technology Press, Beijing, China, 1990, in Chinese.

[22] M. D. Aminu, S. A. Nabavi, and V. Manovic, " $\mathrm{CO}_{2}$-brine-rock interactions: the effect of impurities on grain size distribution and reservoir permeability," International Journal of Greenhouse Gas Control, vol. 78, pp. 168-176, 2018.

[23] A. Bolla and P. Paronuzzi, "Numerical investigation of the pre-collapse behavior and internal damage of an unstable rock slope," Rock Mechanics and Rock Engineering, vol. 53, no. 5, pp. 2279-2300, 2019. 
[24] S. Yin, L. Dong, X. Yang, and R. Wang, "Experimental investigation of the petrophysical properties, minerals, elements and pore structures in tight sandstones," Journal of Natural Gas Science and Engineering, vol. 76, Article ID 103189, 2020.

[25] R. E. Goodman, Introduction to Rock Mechanics, Wiley, New York, NY, USA, 1980.

[26] F. Dai, S. Huang, K. Xia, and Z. Tan, "Some fundamental issues in dynamic compression and tension tests of rocks using split Hopkinson pressure bar," Rock Mechanics and Rock Engineering, vol. 43, no. 6, pp. 657-666, 2010.

[27] H. Du, F. Dai, K. Xia, N. Xu, and Y. Xu, "Numerical investigation on the dynamic progressive fracture mechanism of cracked chevron notched semi-circular bend specimens in split Hopkinson pressure bar tests," Engineering Fracture Mechanics, vol. 184, pp. 202-217, 2017.

[28] X. Li, Y. Zou, and Z. Zhou, "Numerical simulation of the rock SHPB test with a special shape striker based on the discrete element method," Rock Mechanics and Rock Engineering, vol. 47, no. 5, pp. 1693-1709, 2014.

[29] J. Wang, J. Ning, P. Qiu, Y. Shang, and H. Sheng, "Microseismic monitoring and its precursory parameter of hard roof collapse in longwall faces: a case study," Geomechanics and Engineering, vol. 17, no. 4, pp. 375-383, 2019.

[30] J. Wang, P. Qiu, J. Ning, L. Zhuang, and S. Yang, “A numerical study of the mining-induced energy redistribution in a coal seam adjacent to an extracted coal panel during longwall face mining: a case study," Energy Science \& Engineering, vol. 8, no. 3, pp. 817-835, 2020. 